\title{
O EFEITO DO TREINO DA VISÃO PERIFÉRICA NA CORRELAÇÃO ENTRE CHUTES PARA O GOL E TENTOS REALIZADOS NO FUTSAL
}

Nelson Kautzner Marques Junior

Guilherme Soares Garcia

Vernon Furtado da Silva

\section{Resumo}

O objetivo do estudo foi determinar o efeito do treino da visão periférica na correlação entre chutes para o gol e tentos realizados no futsal. A amostra foi composta por dez meninos com 10,4 $\pm 2,31$ anos que foram divididos entre grupo experimental (GE) e grupo controle (GC). Esses jovens realizaram 25 sessões, o GE praticou o treino da visão periférica (TVP), enquanto que o GC realizou 15 sessões do treino tradicional e se exercitou em 10 sessões do TVP. O TVP ensina o futebolista a atuar na partida com ênfase na visão espacial através do treino técnico, treino situacional, treino tático e no jogo. $\mathrm{O}$ campeonato em dupla foi filmado pela câmera Sony Handycam Vision CCD-TRV 12 e posteriormente foram quantificados os chutes e gols das respectivas zonas da quadra por scout. Os resultados apresentaram um $\mathrm{r}$ insignificante $(\mathrm{p}>0,05)$ por zona do campo do GE e do GC. Todas as zonas da quadra foram significantes $(\mathrm{p} \leq 0,05)$ para o $\mathrm{GC}(\mathrm{r}=-0,97)$ e insignificante $(\mathrm{p}>0,05)$ para o GC. Concluindo, nesta pesquisa foi evidenciado que o mais importante é a precisão do chute que resulta em gol e não a alta quantidade desse fundamento no jogo.

\section{Palavras-Chave:}

Futebol de salão; Gol; Chute; Visão periférica.

\section{THE EFFECT OF THE PERIPHERAL VISION TRAINING OF THE CORRELATION BETWEEN KICK AND GOALS IN INDOOR SOCCER}

\begin{abstract}
The objective of the study was of determines the effect of the peripheral vision training (PVT) of the correlation between kick and goals. Ten young indoor soccer players with an average of 10,4 $\pm 2,31$ years old participated in the study with two groups, experimental group (EG) and control group (CG). Each subjects trained 25 sessions, EG practiced peripheral vision training (PVT), but CG was 15 sessions of the traditional training and practiced 10 sessions of the PVT. The PVT teaches the indoor soccer player has emphasis of the peripheral vision in match. The PVT the indoor soccer player practices of the technical training, of the mine-game, of the tactical training and of the match. The championship in double was filmed by the camera Sony Handycam Vision CCD-TRV 12 and later the kicks and goals of the respective zone of the field were analyses by scout. The results presented an insignificant $(p>0,05)$ for zone of the field of the EG and of the CG. All zones of the field were significant $(p \leq 0,05)$ for the $C G(r=$ - 0,97) and insignificant $(p>0,05)$ for the EG. In conclusion, in this research it was evidenced that most important it is the precision of the kick that results in goal and more kick with bad direction not is important for the indoor soccer.
\end{abstract}

\section{Key-Words:}

Indoor soccer; Goal; Kick; Peripheral vision 


\section{Introdução}

As modalidades coletivas caracterizam-se por uma disputa entre o modelo de jogo de duas equipes (McGARRY; FRANKS, 2007), quando acontece um confronto constante do ataque versus a defesa (DAOLIO, 2002). No futebol de salão (futsal), o objetivo é marcar um maior número de tentos que proporciona a vitória, que é, geralmente, conseguido através das tentativas de chutes para o gol (AMARAL; GARGANTA, 2005). Segundo a literatura, as maiores chances de gol acontecem com pouca troca de passe numa alta velocidade ou num pequeno número de toques na bola numa ação veloz porque esse tipo de tarefa não dá tempo para a defesa se posicionar adequadamente (HUGHES; FRANKS, 2005; MARQUES JUNIOR, 2004). Geralmente os gols ocorrem no final do primeiro e do segundo tempo, uma das causas é o cansaço físico e os baixos estoques de glicogênio muscular (DIAS; SANTANA, 2006; DINIZ DA SILVA, 2006). Talvez esse elevado número de gols na etapa final aconteça porque uma equipe realizou mais chutes para o gol do oponente (ENSUM TAYLOR; WILLIAMS, 2002). Mas para tal fato ocorrer é necessário adequada técnica desportiva (PAPADIMITRIOU; AGGELOUSSIS; DERRI; MICHALOPOULOU; PAPAS, 2001) somada a uma eficaz seqüência ofensiva (SILVA; BAÑUELOS; GARGANTA; ANGUERRA, 2005). Porém, para determinar se o maior número de chutes ocasiona mais chances de gol, O`Shaughnessy (2006) recomenda a quantificação de chutes e de gols para serem tratados pela estatística.

Segundo Garganta (2001), a análise do jogo da atualidade se torna relevante quando o pesquisador faz uma ou mais investigações sobre a partida, como: Quem realizou a jogada?, Como e de que tipo é praticada a ação?, Onde foi executada a atividade?, Quando é efetuada essa tarefa?, Esses fundamentos e/ou ações táticas foram boas ou ruins? E porque as pesquisas sobre uma variável na partida do futsal são escassos (ARINS; ROSENDO DA SILVA, 2007) e esta investigação que tenta determinar a relação de chutes para meta e gols parece ser a primeira (SOARES; TOURINHO FILHO, 2006). Recentemente, vários estudos afirmaram que o adequado campo visual proporciona um chute para a meta com mais chances de gol (FINNOFF; NEWCOMER; LASKOWSKI, 2002; McGARRY; FRANKS, 2000; VAN DER KAMP, 2006). Pinto e Araújo (1999) recomendaram o treino da visão periférica que ensina ao futebolista de salão a atuar na partida com ênfase na visão espacial porque o atleta acostuma a jogar com a cabeça no plano de Frankfurt. Uma maior informação visual aumenta a percepção (MORENO et al., 2005), melhora a velocidade de reação (SPARROW; BEGG; PARKER, 2006) ocasionando chutes de maior qualidade para o gol (FORD; HODGES; HUYS; WILLIAMS, 2006). Será que a equipe com melhor campo visual realiza mais chutes para a meta e faz mais gols? As referências do futsal não podem 
responder (AVELAR et al., 2007). Então, o objetivo do estudo foi determinar o efeito do treino da visão periférica na correlação entre chutes para o gol e tentos realizados no futsal.

\section{Sujeitos}

Os sujeitos do estudo eram meninos da comunidade de Ititioca e Atalaia, Niterói, Rio de Janeiro. Participavam do Projeto de Esportes do orfanato Lar da Criança Padre Franz Neumair, em Ititioca. O grupo da investigação de atletas de futsal não federados inicialmente era de 16, mas após algumas desistências a pesquisa prosseguiu com 10 jogadores, oito na linha e dois no gol. Esses 10 meninos

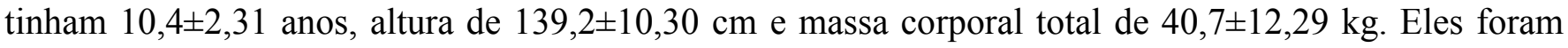
observados jogando futsal quando ocorreu uma divisão intencional da equipe em grupo experimental $(\mathrm{GE}, \mathrm{n}=5)$ e grupo controle $(\mathrm{GC}, \mathrm{n}=5)$ conforme a qualidade técnica e tática de cada atleta, ou seja, a formação dos grupos foi equilibrada em relação ao jogar futsal. Garganta (1995) classificou o nível de jogo dos sujeitos na fase de descentração, onde acontece elevada utilização da visão central. Todos os participantes da pesquisa foram informados sobre a natureza do estudo. Essa investigação respeitou todas as normas do Conselho Nacional em Saúde (1997) envolvendo seres humanos. Os pais dos jovens do futsal liberaram os meninos para o estudo através de um termo de consentimento e o presente trabalho foi aprovado pelo Comitê de Ética em Pesquisa da UCB de acordo com a Resolução 196/96 - protocolo número 0028/2007.

\section{Teste de CLEM}

A hemisfercidade dos jovens atletas de futsal foi estabelecida pelo teste de CLEM de acordo com as informações de Oliveira, Beltrão e Silva (2003).

\section{Treino dos Sujeitos e Colocação no Campeonato em Dupla}

Os atletas de futsal não-federados se encontravam na etapa de especialização inicial, treinavam duas vezes por semana no período de 9 às 10 horas da manhã. Esses jovens praticaram 25 sessões, o GE realizou 25 sessões do treino da visão periférica e o GC se exercitou em 15 sessões tradicionais dessa modalidade e fez antes do $3^{\circ}$ turno, 10 sessões do treino da visão periférica. $O$ modelo de periodização prescrito para a amostra foi a periodização tática que determina que o treino precisa estar centrado no jogo (GOMES, 2006). Para este modelo de periodização ficar adequado ao estudo, foram realizadas algumas adaptações recomendadas por Marques Junior (2007). No macrociclo um foram prescritos 9 sessões de prática em bloco, compostas pelo treino técnico e depois o jogo. Cada tipo de sessão durou 30 minutos, mas no treino técnico o GE se exercitou com um professor e o GC trabalhou com outro 
Educador Físico. Cada amostra ocupou meia quadra para realizar essas atividades. O GE e o GC praticaram os mesmos exercícios técnicos, com as seguintes tarefas: condução da bola, passe, chute, drible, cabeçada, domínio, cruzamento para área, cobrança de penalty, corner, tiro de canto e cobrança de falta direta. Esses fundamentos eram praticados isoladamente e também com a união de alguns deles, por exemplo, conduz a bola até $1 \mathrm{~m}$ e depois chuta para o gol. A única diferença do trabalho do GE para o GC foi ensinar a jogar de cabeça erguida que enfatiza o uso da visão periférica. Terminado o treino técnico, ocorria um jogo do GE versus o GC. O GE tinha que atuar na partida com prioridade nas jogadas no plano de Frankfurt, se abaixar por muito tempo a cabeça perdia a bola, passando para o GC. Como jogar de cabeça erguida ocasionou um decréscimo neuromotor do GE, para equilibrar o jogo o GC só podia dar dois toques na bola. Finalizada as 9 sessões do macrociclo um, aconteceu o $1^{\circ}$ turno do campeonato em dupla de futsal, com as seguintes colocações: $1^{\circ}$ lugar GC A, $2^{\circ}$ lugar GE B, $3^{\circ}$ lugar GE A e $4^{\circ}$ lugar GC B. Os goleiros o $1^{\circ}$ lugar foi para o GE e o $2^{\circ}$ lugar foi para o GC. No macrociclo dois foram prescritas 6 sessões, dois treinos de prática em bloco para averiguar o aprendizado do macrociclo um pelos jovens através do treino cognitivo. O GE tinha que estruturar uma sessão para a sua amostra e o mesmo o GC realizou para sua equipe. Os professores prescreveram o treino cognitivo para se certificarem de que esses meninos poderiam receber um conteúdo mais complexo. Após este ocorrido aconteceram quatro sessões de prática aleatória. A ênfase do trabalho foi o treino situacional e o jogo, os dois tipos de treino duraram cada um 30 minutos. A tarefa prescrita no treino situacional foi composta de mini-jogos, acontecendo em meia quadra, sendo 2 contra 2 e possuindo um goleiro. Neste treino ocorreram três ataques de uma dupla e outra defendendo, em seguida, a dupla que foi fixo (é o beque do futsal) passou a atacar. A diferença do treino situacional do GE para o GC era o predomínio na visão espacial. No treino situacional do GE havia outra diferença, caso o atleta abaixa-se a cabeça por muito tempo era marcado penalty. Para caracterizar a prática aleatória, a sessão do GE e do GC de vez em quando era interrompida sem uma ordem pré-estabelecida, quando os meninos realizavam atividades de outros desportos, atividade realizada pelos dois grupos. Os jovens praticaram a cortada do voleibol, após algumas dessas ações, o professor ensinava cabeçada com balanceio dos braços para proporcionar maior elevação do centro de gravidade. O mesmo foi ensinado para a saída do gol com bola aérea. Após esse exercício os jogadores ou retornavam para o treino situacional ou acontecia outro desporto para o atleta ser orientado a fazer transferência para o futsal. As outras modalidades foram as seguintes: salto em distância, essa técnica devia permitir ao desportista chegar antes na bola, $10 \mathrm{~m}$ rasos, para os jogadores correrem com mais rapidez através da técnica do velocista em certos momentos do futsal e o salto triplo, para o futebolista saltar por cima do goleiro num lance de ataque da partida. Após o treino situacional era 
realizado o jogo do GE versus o GC. Mas nesse macrociclo dois, as partidas passaram a ser realizadas conforme a regra oficial. Finalizadas as 6 sessões do macrociclo dois, aconteceu o $2^{o}$ turno do campeonato em dupla, com as seguintes colocações: $1^{\circ}$ lugar GE B, $2^{\circ}$ lugar GE A, $3^{\circ}$ lugar GC A e $4^{\circ}$ lugar GC B. Os goleiros o $1^{\circ}$ lugar foi para o GE e o $2^{\circ}$ lugar para o GC. No macrociclo três foram prescritas 10 sessões, seis treinos de prática em bloco que iniciaram esse trabalho e quatro sessões de prática aleatória compostas pelas mesmas modalidades do macrociclo dois, tendo o treino tático e depois o jogo, com duração de 30 minutos cada tipo de atividade. O GE e o GC realizaram o treino tático juntos, utilizando toda a quadra. As duas amostras praticaram na sessão tática o treino da visão periférica que educa a jogar de cabeça erguida. No treino tático os atletas aprenderam a "rodar", isto é, os jogadores trocavam de posição (ala para o pivô, pivô para fixo etc) visando progredir da defesa para o ataque. Essa sessão foi conduzida com jogadores do GE e do GC se exercitando na mesma equipe e orientadas por dois professores. O treino tático foi prescrito com as seguintes variações: feito sem bola, sem marcação, com marcação em meia quadra e com marcação em toda a quadra. Terminada esta tarefa era realizado o jogo, possuindo cada equipe atletas do GE e do GC, e esses desportistas eram obrigados a efetuar as atividades "rodando" e na maior parte da partida com predomínio da visão periférica. Caso esses dois procedimentos não fossem realizados, a equipe perdia a posse da bola. Finalizada as 10 sessões do macrociclo três, aconteceu o $3^{\circ}$ turno do campeonato em dupla, com as seguintes colocações: $1^{\circ}$ lugar GC $\mathrm{B}, 2^{\circ}$ lugar GE B, $3^{\circ}$ lugar GC A e $4^{\circ}$ lugar GE A. Os goleiros o $1^{\circ}$ lugar foi para o GC e o $2^{\circ}$ lugar para o GE. Os resultados dos três turnos credenciaram o GE como vencedor do campeonato na linha e no gol.

\section{Regulamento do Campeonato em Dupla, Coleta de Dados e Análise dos Jogos}

No campeonato em dupla foram praticadas as seguintes tarefas por três tentativas:

a) Todo início das tarefas $\mathrm{B}$ a E começam com saída do meio-campo.

b) Quando o juiz apitar! O atleta deve praticar uma seqüência ofensiva para frente até realizar a finalização. Todos precisam tocar na bola, caso contrário a tentativa é desperdiçada.

c) Quando o juiz apitar! O atleta deve realizar uma seqüência ofensiva, mas tendo a marcação de dois atletas que saem numa corrida de 3,5 m ( $3^{\mathrm{a}}$ linha) vindo por trás do atacante e tentam interceptar o ataque. Todos precisam tocar na bola, caso contrário a tentativa é desperdiçada.

d) Quando o juiz apitar! O atleta deve realizar uma seqüência ofensiva, mas tendo dois defensores posicionados ao lado dos atacantes. Esses zagueiros inicialmente se localizam numa distância de 4,40 m 
(linha amarela), dado o início da tarefa eles podem chegar perto dos atacantes para interceptar a tática ofensiva. Todos precisam tocar na bola, caso contrário a tentativa é desperdiçada.

e) Quando o juiz apitar! O atleta deve realizar uma seqüência ofensiva, mas tendo dois defensores de frente para os atacantes. Esses zagueiros inicialmente se localizam numa distância de 6,46 m (linha branca), dado o início da tarefa eles podem chegar perto dos atacantes para interceptar a tática ofensiva. Todos precisam tocar na bola, caso contrário a tentativa é desperdiçada.

f) Ocorre um revezamento no ataque das tarefas da letra A-D, após três tentativas de uma dupla, por exemplo, na tarefa A, ocorre o ataque da outra dupla na mesma atividade. O mesmo acontece com os goleiros. Quando o GE ataca o goleiro é do GC, acontecendo ataque do GC o guarda-rede é do GE. Mas quando joga o GE contra o GE o goleiro é da mesma amostra o mesmo é determinado para o GC.

O campeonato em dupla de futsal foi composto pelos seguintes duetos: GE A, GE B, GC A e GC B. Cada amostra dispunha de um goleiro, e a disputa ocorreu em meia quadra com $12 \mathrm{~m}$ de comprimento por 13,98 m de largura. Para que o pesquisador posicionado na lateral da meia quadra e em cima de uma cadeira, filmasse com a filmadora Sony Handycam Vision CCD-TRV 12 e fita Sony Digital 8 mm todos os jogos de cada turno (4 por campeonato), num total de 12 partidas. Os recursos tecnológicos (filmadora e televisão) utilizados nesta pesquisa foram baseados em Jackson e Baker (2001). Posteriormente a filmagem do campeonato em dupla foi analisada pelo scout do anexo passando a imagem da filmadora via fio ouro para a televisão CCE de 30 polegadas, com o mesmo professor que ficou sentado a $87 \mathrm{~cm}$ da televisão para capturar os gols e os chutes nas respectivas zonas da quadra. Durante esse estudo da partida ele utilizou o controle remoto da filmadora quando necessário com seus respectivos recursos especiais (voltar, avançar, parar e pausa).

\section{Tratamento Estatístico}

Para análise estatística foi estabelecida a média, o desvio padrão e o coeficiente de correlação Pearson, com nível de significância de $\mathrm{p} \leq 0,05$. Toda estatística foi calculada conforme os procedimentos do SPSS 12.0 for Windows.

\section{Resultados e Discussão}

A figura um expõe a hemisfericidade das duplas e dos goleiros do estudo. 


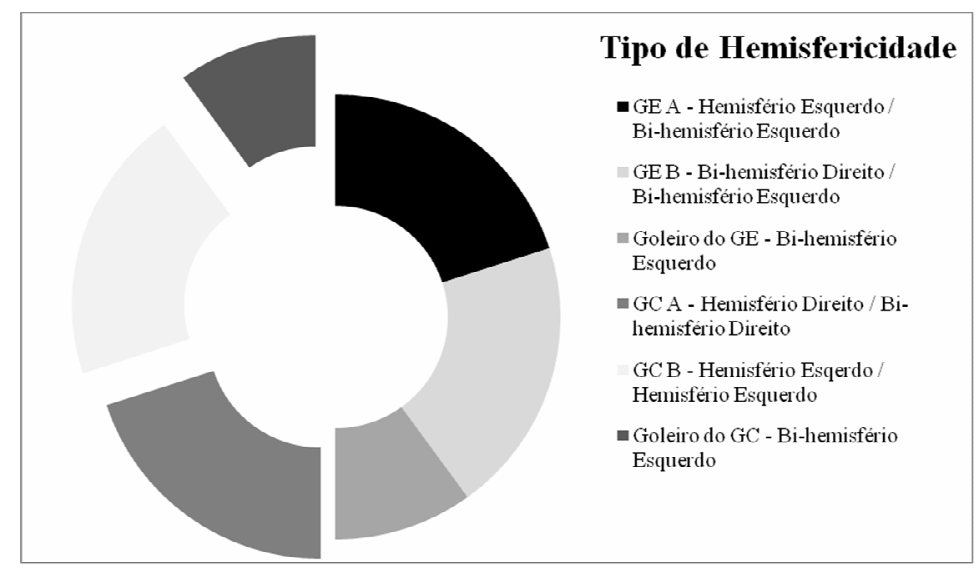

Figura 1- Tipo de hemisfério de processamento mental do GE e do GC.

A figura dois mostra as zonas onde ocorreram os chutes e os gols para leitor ter melhor entendimento das tabelas a seguir:

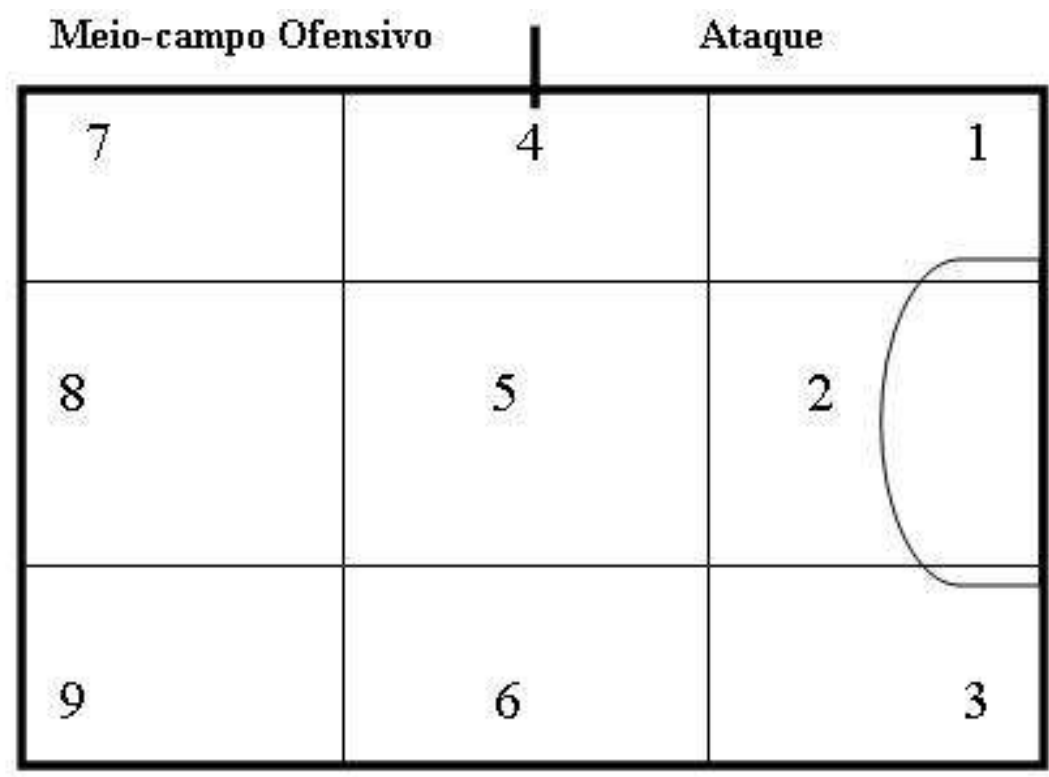

Figura 2 - Zonas da quadra onde aconteceram os chutes e os gols. 
A Tabela 1- apresenta a estatística descritiva dos chutes para o gol conforme a zona da quadra.

Tabela 1 - Chutes para Gol na Respectiva Zona de Quadra

\begin{tabular}{ccccccc}
\hline Grupo & Zona 2 & Zona 3 & Zona 5 & Zona 6 & Zona 8 & Todas as zonas \\
\hline GE & $5,50 \pm 1,91$ & $0,50 \pm 0,5$ & $7,50 \pm 4,65$ & $1 \pm 1,15$ & $1,75 \pm 1,25$ & $16,5 \pm 4,5$ \\
& & & & & & \\
GC & $4 \pm 3,55$ & - & $7 \pm 2,16$ & - & $5,50 \pm 3,31$ & $13,25 \pm 6,39$ \\
\hline
\end{tabular}

A Tabela 2- expõe a estatística descritiva dos gols conforme a zona da quadra.

Tabela 2 - Gols na Respectiva Zona da Quadra

\begin{tabular}{ccccccc}
\hline Grupo & Zona 2 & Zona 3 & Zona 5 & Zona 6 & Zona 8 & Todas as zonas \\
\hline GE & $9 \pm 2,94$ & $0,25 \pm 0,5$ & $7 \pm 1,41$ & $0,25 \pm 0,5$ & $0,50 \pm 0,5$ & $17 \pm 3,8$ \\
GC & $9 \pm 3,36$ & - & $4,25 \pm 0,9$ & - & $1,75 \pm 1,7$ & $15,25 \pm 2,75$ \\
\hline
\end{tabular}

A Tabela 3 - mostra a correlação de Pearson entre as variáveis do estudo.

Tabela 3 - Resultados do R De Pearson Conforme a Zona da Quadra

\begin{tabular}{llcccccc}
\hline Grupo & \multicolumn{1}{c}{ Variável } & Zona 2 & Zona 3 & Zona 5 & Zona 6 & Zona 8 & $\begin{array}{c}\text { Todas as } \\
\text { zonas }\end{array}$ \\
\hline GE & $\begin{array}{l}\text { Chutes para o gol } \mathrm{x} \\
\text { Gols }\end{array}$ & 0,23 & $-0,57$ & 0,30 & $-0,57$ & 0,22 & $-0,65$ \\
$\mathrm{GC}$ & & 0,94 & - & 0,80 & & 0,61 & $-0,97 *$ \\
\hline "p $\leq 0,05$ (significativo) & & & & & &
\end{tabular}

Os resultados do estudo demonstraram uma insignificante ( $p>0,05)$ correlação de Pearson para o GE e para o GC. O GE tinha $80 \%$ de hemisfério esquerdo e $20 \%$ de jogadores de hemisfério direito. Verstynen, Diedrichsen, Albert, Aparicio e Ivry (2005) foram a favor dessas afirmações, a hemisfericidade esquerda que não permitiu uma correlação (r) significativa do GE. Mesmo praticando 25 sessões do treino da visão periférica, o hemisfério de maior quantidade prejudicou essa amostra. Greco (2006) não concordou, o problema principal do GE foi técnico e tático, a hemisfericidade foi uma das causas. Naito; Roland; Grefkes; Choi; Eickhoff; Geyer; Zilles e Ehrsson (2005) foram a favor desse último autor, o GC tinha hemisfericidade parecida com o GE, $60 \%$ de hemisfério esquerdo e $40 \%$ de hemisfério direito. Isto pode ser afirmado porque o hemisfério direito é ótimo para tarefas motrizes e a hemisfericidade esquerda tem melhor desempenho em atividades analíticas. 
O GE realizou os chutes e gols no ataque (zona 2 e 3), no meio-campo ofensivo e no ataque (zona 5 e 6 ) e no meio campo ofensivo (zona 8). Já o GC concentrou seus chutes e gols no ataque (zona 2), no meiocampo ofensivo e no ataque (zona 5) e no meio-campo ofensivo ocorrem mais gols (VILHENA SILVA et al., 2005). Harle; Vickers (2001) não entenderam o $\mathrm{r}$ insignificante do GE, quando um técnico se preocupa com a visão o desportista leva vantagem. Com o que Reina, Moreno e Sanz (2007) concordaram. Williams; Hodges (2005) explicaram o r insignificante do GE, o motivo foi a prescrição de poucas sessões da prática aleatória, os jogadores do GE não atingiram retenção do treino da visão periférica. Ré, Rose Junior; Böhme (2004) lembraram outro ocorrido, a amostra do estudo viveu sua primeira experiência competitiva, talvez o stress da disputa tenha interferido o GE.

Lee, Legge; Ortiz (2003) acharam que o problema do GE foi o número baixo de sessões do treino da visão periférica, apenas 25 , por esse motivo a visão espacial não causou um efeito no $r$ dessa pesquisa. Gréhaigne; Godbout; Bouthier (2001) acusaram uma limitação do estudo, o autor não mensurou a tomada de decisão no momento do chute para o gol. Suzuki e Nishijima (2007) identificaram outro problema, a investigação não determinou a qualidade defensiva das duplas. Será que o GC tinha melhor defesa? Não se pode afirmar, mas pode ser uma causa do $r$ insignificante do GE. Então nesse estudo, parece que o jargão dos locutores é verdade (Quem não faz toma!!!). Um grande número de tentativas de chutes para o gol não quer dizer que vai acontecer muitos tentos. Uma equipe pode realizar vinte chutes sem gol e outra marcar em apenas três tentativas. Contudo, esta investigação foi no futsal adaptado. Para Barfield; Kirkendall; $\mathrm{Yu}$, (2002) o que afetou no $\mathrm{r}$ do estudo foi a fraca biomecânica do remate que esses jovens costumam ter na iniciação. Além deste problema, Sousa, Garganta e Garganta (2003) acrescentaram que os níveis de força na faixa etária do estudo costumam ser baixa, afetando o chute.

Bray; Kerwin (2003) lembraram que a aerodinâmica da bola pode ser outra causa do treino da visão periférica não otimizar o $\mathrm{r}$ do GE, conforme a qualidade do material o implemento toma outra direção.

São muitas divergências e limitações dessa pesquisa, onde foi mostrado que o treino da visão periférica não causou um incremento do $\mathrm{GE}$ em relação ao $\mathrm{GC}$, apenas proporcionou a vitória desses sujeitos no campeonato em dupla de futsal.

\section{Considerações Finais}

O GE praticou 25 sessões do treino da visão periférica não conseguindo um $r$ significativo $(p>0,05)$. Porém, o GE foi o campeão da disputa em dupla, talvez a causa seja o treino da visão periférica. O GC quando recebeu o estímulo do treino da visão periférica antes do $3^{\circ}$ turno foi o campeão dessa etapa. 
Estes ocorridos parecem evidenciar que jogar de cabeça erguida causa um incremento no resultado final do futsal. Assim o que é falado nas transmissões do futebol, foi mostrado nesta pesquisa para o futsal adaptado: Quem não faz toma!!! Um time pode efetuar 20 chutes e não marcar nenhum gol, sendo superior em todos os momentos do jogo. Mas outra equipe, inferior o tempo todo na partida, fez três chutes em direção à meta e conseguiu um tento. Então, através desse estudo pode-se concluir que o futsal é uma modalidade de difícil prognóstico no resultado do jogo porque nem sempre quem chutou mais vence a partida. O diferencial é a qualidade do chute em direção a meta, ou seja, a precisão desse fundamento.

\section{Referências}

AMARAL, R.; GARGANTA, J. A modelação do jogo em futsal. Análise seqüencial do 1x1 no processo ofensivo. Revista Portuguesa de Ciências do Desporto, v. 3, n. 5, p. 298-310, 2005.

ARINS, F. B.; SILVA, R. R. C. Intensidade de trabalho durante os treinamentos coletivos de futsal profissional: um estudo de caso. Revista Brasileira de Cineantropometria, v. 9, n. 3, p. 291-296, 2007.

AVELAR, A. et al. Perfil antropométrico e de desempenho motor de atletas paranaenses de futsal de elite. Revista Brasileira de Cineantropometria e Desempenho Humano, v. 10, n. 1, p. 76-80, 2008.

BARFIELD, W. R.; KIRKENDALL, D. T.; YU, B. Kinematic instep kicking differences between elite female and male soccer players. Journal of Sports Sciences and Medicine. v. 1, n. -, p. 72-79, 2002.

BRAY, K.; KERWIN, D. G. Modelling the flight of a soccer ball in a direct free kick. Journal of Sports Sciences. v. 21, n. 2, p. 75-85, 2003.

DAOLIO, J. Jogos esportivos coletivos: dos princípios operacionais aos gestos técnicos-modelo pendular a partir das idéias de Claude Bayer. Revista Brasileira de Ciência e Moviment. v. 10, n. 4, p. 99-104, 2002.

DIAS, R. M.; SANTANA, W. C. Tempo de incidências dos gols em equipes de diferentes níveis competitivos na copa do mundo de futsal. Revista Digital, v. 11, n. 101, p. 1- 6, 2006. Disponível em: www.efdeporetes.com/ Acesso em: 21 nov. 2006.

DINIZ DA SILVA, C. Fadiga: evidências nas ocorrências de gols no futebol internacional de elite. Revista Digital, v. 11, n. 97, p. 1-8, 2006. Disponível em: <http://www.efdeportes.com>. Acesso em: 4 ago. 2006.

ENSUM, J.; TAYLOR, S.; WILLIAMS, M. A quantitive analysis of attacking set plays. Insight, v. 4, n. 5, p. 68-72, 2002. 
FINNOFF, J. T.; NEWCOMER, K.; LASKOWSKI, E. R. A valid and reliable method for measuring the kicking accuracy of soccer players. Journal of Science and Medicine in Sport, v. 5, n. 4, p. 348-353, 2002.

FORD, P.; HODGES, N. J.; HUYS, R.; WILLIAMS, M. The role of external action-effects in the execution of a soccer kick: a comparison across skill level. Motor Control, v. 10, n. 4, p. 386-404, 2006.

GARGANTA, J. Para uma teoria dos jogos desportivos coletivos. In: GRAÇA, A.; OLIVEIRA, J. (Ed.). O ensino dos jogos desportivos. 2. ed. Porto: Universidade do Porto, 1995. p. 25-35.

GARGANTA, J. A análise da performance nos jogos desportivos. Revisão acerca da análise do jogo. Revista Portuguesa de Ciências do Desporto, v. 1, n. 1, p. 57-64, 2001.

GRECO, P. J. Conhecimento tático-técnico: eixo pendular da ação tática (criativa) nos jogos esportivos coletivos. Revista Brasileira de Educação Física e Esporte, v. 20, supl. 5, p. 210-212, 2006.

GRÉHAIGNE, J.-F.; GODBOUT, P.; BOUTHIER, D. The teaching and learning of decision making in team sports. Quest, v. 53, n. 1, p. 59-76, 2001.

GOMES, M. S. Do pé como técnica ao pensamento técnico dos pés dentro da caixa preta da periodização tática: um estudo de caso. Porto: Universidade do Porto, 2006.

HARLE, S. K.; VICKERS, J. N. Training quiet eye improves accuracy in the basketball free throw. The Sport Psychologist, v. 15, n. 3, p. 289-305, 2001.

HUGHES, M.; FRANKS, I. Analysis of passing sequences, shots and goals in soccer. Journal of Sports Sciences, v. 23, n. 5, p. 509-514, 2005.

JACKSON, R. C.; BAKER, J. S. Routines, rituals, and rugby: case study of a world class goal kicker. The Sport Psychologist, v. 15, n. 1, p. 48-65, 2001.

LEE, H.-W.; LEGGE, G. E.; ORTIZ, A. Is Word recognition different in central and peripheral visión? Vision Research, v. 43, n. -, p. 2837-2846, 2003.

LEVANDOSKI, G.; CARDOSO, F. L.; CIESLAK, F. Perfil somatótipo, variáveis antropométricas, aptidão física e desempenho motor de atletas juvenis de futsal feminino da cidade de Ponta Grossa/PR Brasil. Fitness and Performance Journal, v. 6, n. 3, p. 162-166, 2007.

MARQUES JUNIOR, N. K. Solicitação metabólica no futebol profissional masculino e o treinamento cardiorrespiratório. Revista Corpoconsciência, n. 13, p. 25-58, 2004.

MARQUES JUNIOR, N. K. Periodização tática: o treinamento de iniciadas do futebol de salão feminino de 2006. Movimento e Percepção. v. 8, n. 11, p. 7-41, 2007.

McGARRY, T.; FRANKS, I. M. On winning the penalty shoot-out in soccer. Journal of Sports Scienc. v. 18, n. 6, p. 401-409, 2000. 
McGARRY, T.; FRANKS, I. M. System approach to games and competitive playing: reply to Lebed (2006). European Journal of Sports Sciences. v. 7, n. 1, p. 47-53, 2007.

MORENO, F. J. et al. R. Visual behavior and perception of trajectories of moving objects with visual occlusion. Perceptual and Motor Skills, v. 101, n. 1, p. 13-20, 2005.

NAITO, E. et al. Dominance of the right hemisphere and role of area 2 in human kinesthesia. Journal of Neurophysiology, v. 93, n. -, p. 1020-1034, 2005.

OLIVEIRA, F. A.; BELTRÃO, F. B.; SILVA, V. F. da. Metacognição e hemisfericidade em jovens atletas. Revista Paulista de Educação Física, v. 17, n. 1, p. 5-15, 2003.

O 'SHAUGHNESSY, D. M. Possession versus position: strategic evaluation in AFL. Journal of Sports Science and Medicine. v. 5, p. 533-540, 2006.

PAPADIMITRIOU, K. et al. Evaluation of the offensive behavior of elite soccer teams. Perceptual and Motor Skills. v. 93, n. 2, p. 405-415, 2001.

PINTO, J. A.; ARAÚJO, N. I. Importância do treinamento da visão periférica no futebol. Revista Mineira de Educação Física, v. 7, n. 2, p. 81-93, 1999.

RÉ, A. H. N.; ROSE JÚNIOR, D.; BÖHME, M. T. S. Stress e nível competitivo: considerações sobre jovens praticantes de futsal. Revista Brasileira de Ciência e Movimento, v. 12, n. 4, p. 83-87, 2004.

REINA, R.; MORENO, F. J.; SANZ, D. Visual behavior and motor responses of novice and experienced wheelchair tennis player relative to the service return. Adapted Physical Activity Quarterly. v. 24, n. 3, p. 254-271, 2007.

SILVA, A.; BAÑUElos, F. S.; GARGANTA, J.; ANGUERA, M. T. Patrones de juego en el fútbol de alto rendimiento. Análisis secuencial del proceso ofensivo en el campeonato del mundo Corea-Japón 2002. Cultura, Ciencia y Deporte, v. 1, n. 2, p. 65-72, 2005.

SOARES, B-H; TOURINHO FILHO, H. Análise da distância e intensidade dos deslocamentos numa partida de futsal, nas diferentes posições de jogo. Revista Brasileira de Educação Física e Esporte. v. 20, n. 2, p. 93-101, 2006.

SOUSA, P.; GARGANTA, J.; GARGANTA, R. Estatuto posicional, força explosiva dos membros inferiores e velocidade imprimida à bola no remate em futebol. Um estudo com jovens praticantes do escalão sub-17. Revista Portuguesa de Ciências do Desporto, v. 3, n. 3, p. 27-35, 2003.

SPARROW, W. A.; BEGG, R. K.; PARKER, S. Aging effects on visual reaction time in a single task condition and when treadmill walking. Motor Control, v. 10, n. 3, p. 201-211, 2006.

SUZUKI, K.; NISHIJIMA, T. Sensitivity of the soccer defending skill scale: a comparison between teams. European Journal of Sport Sciences, v. 7, n. 1, p. 35-45, 2007. 
VAN DER KAMP, J. A field simulation study of the effectiveness of penalty kick strategies in soccer: late alterations of kick direction increase errors and reduce accuracy. Journal of Sports Sciences, v. 24, n. 5, p. 467-477, 2006.

VERSTYNEN, T. et al. Ipsilateral motor cortex activity during unimanual hand movements relates to task complexity. Journal of Neurophysiology, v. 93, n. -, p. 1209-1222, 2005.

VILHENA SILVA et al. Comparison between the offensive actions of the final stage of the mineiro championship of indoor soccer in the pre mirim and mirim categories. Fiep Bulletin, v. 75, special number, p. 284-287, 2005.

WILLIAMS, M.; HODGES, N. J. Practice, instruction and skill acquisition in soccer: challenging tradition. Journal of Sports Sciences, v. 23, n. 6, p. 637-650, 2005. 


\section{ANEXO 1}

\section{SCOUT PARA IDENTIFICAR A TÁTICA OFENSIVA DO FUTSAL}

Evento da Filmagem:

Jogo:

Atividade:

Tentativa:

Dupla no Ataque:

Defesa

Meio-campo Defensivo

Meio-campo Ofensivo

Ataque

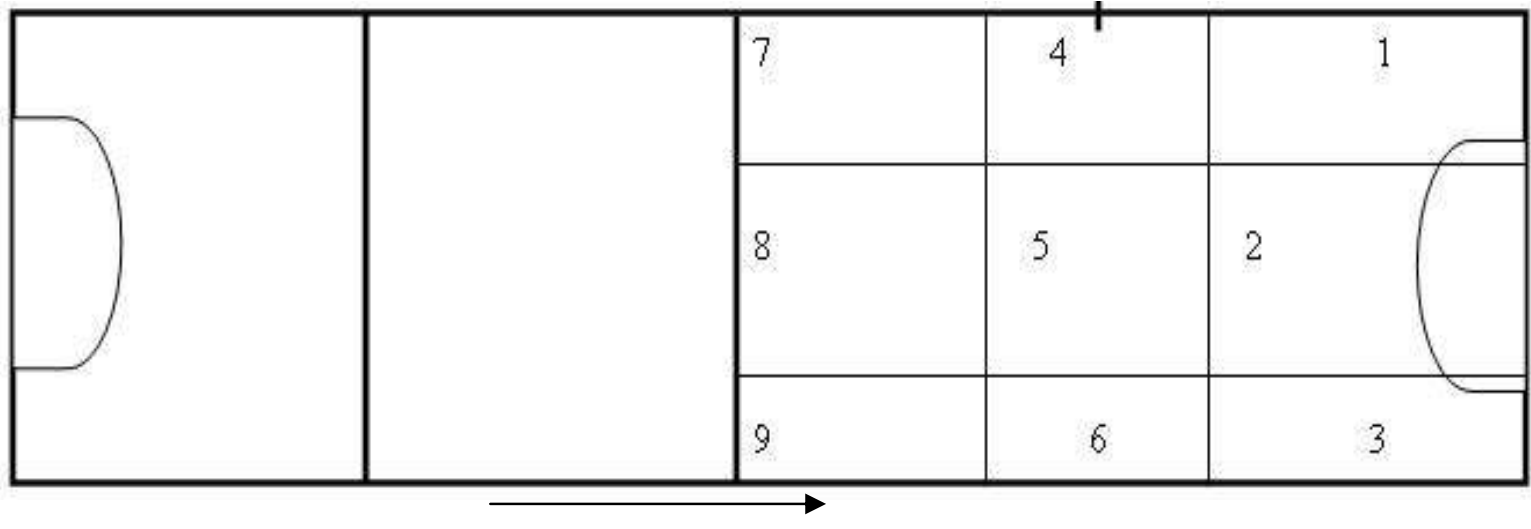

Direção do Ataque

Obs.: O traço que divide o meio-campo ofensivo e o ataque corresponde o cone, o meio da meia quadra. Região denominada de meio-campo ofensivo e ataque. 
Nelson Kautzner Marques Junior

Universidade Castelo Branco

E-mail: nk-junior@uol.com.br / nkjunior@fastmodem.com.br

Mestrando em Ciência da Motricidade Humana pela UCB

\section{Guilherme Soares Garcia}

Lar da Criança Padre Franz Neumair

Pós-Graduado Latu Sensu em Treinamento Desportivo pela UGF

Vernon Furtado da Silva

Universidade Castelo Branco

Pós-Doutorado em Nerociências pela Universidade de Maryland 